\title{
Experimental Study of the Solar Air Heater Performance with Evacuated Tubes Connected in Series and Involving Nano-Copper Oxide / Paraffin Wax as Thermal Storage Enhancer
}

Amr Elbrashy ( $\square$ amr_pg097@eng.kfs.edu.eg )

Kafrelsheikh University Faculty of Engineering https://orcid.org/0000-0002-5508-1632

Fawzy Aboutaleb

: Kafrelsheikh University Faculty of Engineering

Magda El-Fakharany

: Kafrelsheikh University Faculty of Engineering

Fadl Essa

Kafrelsheikh University Faculty of Engineering

\section{Research Article}

Keywords: Evacuated tube collector, Solar air heater, Nanoparticles, Paraffın wax, Thermal efficiency, Air flow rates

Posted Date: March 3rd, 2022

DOI: https://doi.org/10.21203/rs.3.rs-1317287/v1

License: (c) (i) This work is licensed under a Creative Commons Attribution 4.0 International License.

Read Full License 
1 Experimental study of the solar air heater performance with

2 evacuated tubes connected in series and involving Nano-copper

3

4

\title{
oxide / paraffin wax as thermal storage enhancer
}

\author{
Amr Elbrashy, Fawzy Aboutaleb, Magda Elfakharany, Fadl Essa
}

Mechanical Engineering Department, Faculty of Engineering, Kafrelsheikh University,

Kafrelsheikh 33516, Egypt.

\section{Abstract}

The investment of solar energy in life applications has become mandatory in order to maintain a clean environment and reduce the use of fossil fuel. In this work, the performance of solar air heater is aimed to be improved with the help of evacuated tube solar collectors. To achieve this purpose, a system consisting of 5 linked collecting panels was designed, fabricated, and experimentally tested. Each panel included a glass-evacuated tube with two concentric aluminum tube installed inside. The system was reinforce by adding paraffin wax as a PCM and boosting its thermal conductivity by incorporating it with copper oxide nanoparticles $\mathrm{CuO}$. The performance was investigated with and without Nano enhancer phase change material NE-PCM at five mass flow rates $(0.006-$ 0.008-0.05-0.03-0.01 kg/s). Experimental results revaluated that the highest temperature was recorded as $116^{\circ} \mathrm{C}$ at a mass flow rate of $0.006 \mathrm{~kg} / \mathrm{s}$. The maximum thermal efficiency with storage material was $38 \%$ at $0.05 \mathrm{~kg} / \mathrm{s}$, and the pressure drop was about $2.2 \mathrm{kPa}$.

\section{Keywords:}

Evacuated tube collector; Solar air heater; Nanoparticles; Paraffin wax; Thermal efficiency; Air flow rates.

Corresponding author: Amr Elbrashy

Email: $\underline{\text { amr_pg097@eng.kfs.edu.eg }}$

Mechanical Engineering Department, Faculty of Engineering, Kafrelsheikh University, Kafrelsheikh 33516, Egypt. 
30 Ap aperture area solar collector (m2)

$31 \quad \mathrm{Cp} \quad$ specific heat of air $(\mathrm{J} / \mathrm{kg} \mathrm{K})$

32 Do outer diameter of tube (m)

$33 \mathrm{k}$ thermal conductivity (W/m K)

$34 \quad \mathrm{~m}$ mass flow rate of air $(\mathrm{kg} / \mathrm{s})$

$35 \mathrm{~m}$ mass of the PCM $(\mathrm{kg})$

$36 \mathrm{~N}$ total number of tubes

$37 \quad$ Pm pumping work (W)

$38 \quad \mathrm{Qu} \quad$ useful heat gain (W)

39 Qa actual heat absorbed to collector (W)

$40 \mathrm{R}$ insolation of solar radiation $(\mathrm{W} / \mathrm{m} 2)$

41 Ta Ambient temperature (K)

$42 \Delta \mathrm{T} \quad$ change in temperature $(\mathrm{K})$

$43 \Delta \mathrm{P} \quad$ pressure drop $(\mathrm{N} / \mathrm{m} 2)$

$44 \quad \mathrm{H} \quad$ Humidity (\%)

45 Ws Wind speed $(\mathrm{m} / \mathrm{s})$

Abbreviations

48 CPC compound parabolic collector

49 FPSC flat plate collector

$50 \quad$ ETSC Evacuated tube solar collector

$51 \quad$ PCM phase change material

52 Ne-PCM Nano-enhanced PCM

53 HTF heat transfer fluid

54 SAH solar air heater

\section{$55 \quad 1$ Introduction}

56 In light of high-energy costs and strict emission standards, and increasing demand for energy, natural 57 resources and renewable energy must be exploited, which is characterized by economic savings and environmental cleanliness. Solar energy is the most important natural resource because has outstanding advantages, such as vast availability, inexhaustibility, environmental friendliness, extensive distribution and provides various energy as benefit by transform to photovoltaic, thermal, and electric energy. (Khan et al., 2018; P. Singh \& Gaur, 2021).Solar 
collector is a well-known solar thermal energy conversion device that absorbs solar energy and converts it to a flowing fluid (water or air). The most widely used solar collectors involving evacuated tube solar collectors (ETSC), flat-plate solar collectors (FPSC), and compound parabolic concentrators (CPCs) as discussed by Kalogirou (Kalogirou, 2004). ETSC has sparked a lot of interest in both industrial and home applications around the world. This is because they cover a broad range of working temperatures and provide better warm proficiency, besides they have very small convective and radiative losses all while being reasonably priced. (Verma, Gupta, \&

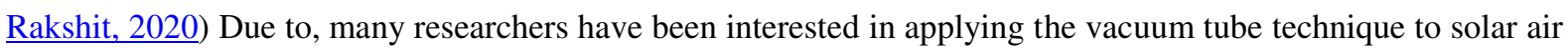
heaters SAH, Its efficiency has been studied, and some modifications have been inserted to improve heat transfer like baffles, helical and concentrating reflective. This makes it more effective for low and medium temperature applications (Korres \& Tzivanidis, 2018; I. Singh \& Vardhan, 2021; Veera Kumar, Arjunan, Seenivasan, Venkatramanan, \& Vijayan, 2021) But the length of the air path has a significant impact on heat transfer because it increases the heat exchange time, and this challange leads to an increase in the number of evacuated tubes in order to extend the air path. Therefore, most of the published papers achieve the experiment between 15-30 vacuum tubes to reach the longest path .

The connection in series between the evacuated tubes was the best solution to double the air path with the least number of evacuated tubes.although this matter was not investigated except in two papers of Wang et al(PinYang Wang et al., 2014; Ping-Yang Wang, Li, \& Liu, 2015) .Reported the outlet temperature reached $230{ }^{\circ} \mathrm{C}$ when using 30 unit connected in series, each unit included a vacuum tube and CPC. In the another research the temperature dropped to 200 when used 10 units, indicating that controlling the number of connected tubes has a direct effect on outlet temperature. Energy storage was an essential role to stay on the energy source when disappearance of sunlight. Therefore, many researchers were interested in study of phase change materials (PCM) and using them with solar heaters in order to store heat for a longer time. (Farid, Khudhair, Razack, \& Al-Hallaj, 2004) In solar air heaters system integrated with PCM, Many research has experimented with acetamide (Mehla \& Yadav, 2016, 2018), paraffin (Abokersh, El-Morsi, Sharaf, \& Abdelrahman, 2017; Algarni et al., 2020; Essa,

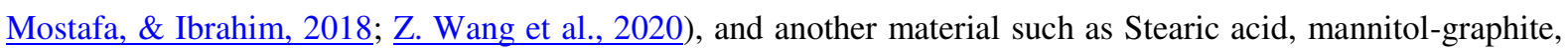
erythritol (Chopra, Tyagi, Pathak, Pandey, \& Sari, 2019; Li \& Zhai, 2017; Yongtai, Lixian, \& Yaohua, 2019) All found that PCM increase the efficiency of thermal performance and the thermal storage where the heat lasts longer after the disappearance of sunlight. More details on evacuated tubes integrated with PCM reviewed in ref) $\underline{\text { Aramesh }}$ \& Shabani, 2020(.Despite the common use of paraffin wax as PCM because it is availability in a wide range of melting points and latent heat capacities, low costs, nontoxicity, physical and chemical stability; but their thermal conductivity is low which negatively affects heat transfer (Chaichan, Abaas, \& Kazem, 2016). One of the solutions discussed to overcome the problem of heat transfer is the addition of nanomaterials, which have physical 
properties that increase thermal conductivity(Qureshi, Ali, \& Khushnood, 2018). Numerous studies were conducted with adding nanoparticles at PCM with different ratios for enhancing the thermal conductivity of storage materials (Abdullah et al., 2020; Nižetić, Jurčević, Arıc1, Arasu, \& Xie, 2020; Olfian, Ajarostaghi, \& Ebrahimnataj, 2020) It was found that the range of thermal conductivity was increased between $20 \%$ and $100 \%$. Nano- enhanced of phase change material (NE-PCM ) integrated with ETSC has discussed by many reviewer; They pointed out that most of the NE-PCM were applied in evacuated tube collectors were $\mathrm{TiO}_{2}, \mathrm{CuO}_{2} \mathrm{Al}_{2} \mathrm{O}_{3}$, $\mathrm{CeO} \mathrm{CeO}_{2}, \mathrm{GNP}, \mathrm{Cu}$ in addition to SWCNTs and MWCNTs have been considered by (Babapoor, Karimi, \& Sabbaghi, 2016; Dsilva Winfred Rufuss, Suganthi, Iniyan, \& Davies, 2018; Kumar, Tiwari, \& Said, 2021; Xiong, Zheng, \& Shah, 2020). To increase the thermal performance of the system, it is critical to select the right material from among the available nanomaterials with the PCM. This emphasises the need of evaluating the physical characteristics of the resultant composites, which will considerably influence the selection of acceptable materials as nanoparticles.

In this work, the solar air heater SAH studied by five unit of evacuated tube connected in series to more the air path and thus boost the heat transfer. The Paraffin wax and copper oxide nanoparticles are mixed to enhance the thermophysical properties and improve the thermal storage performance of SAH to meet the needs of both domestic and industrial customers with simple design and low-cost materials. The experiment was conducted at five different flow rates $(0.006-0.008-0.05-0.03-0.01 \mathrm{~kg} / \mathrm{s})$. Also within three consecutive months June and July and August. The experiment has achieved the thermal performance of the system with NE-PCM. This study is a unique experience in solar air heaters integrated with nanomaterials and serves as a base for future studies in the operation of SAH with evacuated tube connected in series.

\section{Selection of materials}

\subsection{Paraffin wax as PCM}

The use of PCM in solar applications has become mandatory to maintain of more operating time for application, and reducing the thermal fluctuation produced by the instantaneous solar radiation intensity fluctuation. In this work, Paraffin wax $\left(\mathrm{C}_{\mathrm{n}} \mathrm{H}_{2 \mathrm{n}+2}\right)$ it is composed of straight chain hydrocarbons with melting temperatures ranging from 23 to $67^{\circ} \mathbf{C}($ Sharma, Kitano, \& Sagara, 2004) $)$ Paraffin wax is an organic heat storage PCM for commercial uses; it was nominated, as a PCM for several major reasons such as is a reliable, chemically stable, high stability for very long melting cycles, nontoxic, inexpensive, and availability. Therefore, it is a good chosen as a thermal storage material in solar collector systems. Table 1 displays the properties of paraffin wax used in this experimental. 


\begin{tabular}{|c|c|}
\hline Property & Value \\
\hline Melting temperature $\left({ }^{\circ} \mathbf{C}\right)$ & 59 \\
\hline Latent fusion heat $(\mathbf{k J} / \mathbf{k g})$ & 190 \\
\hline Solid state density $\left(\mathbf{k g} / \mathbf{m}^{3}\right)$ & 920 \\
\hline Liquid state density $\left(\mathbf{k g} / \mathbf{m}^{\mathbf{3}}\right)$ & 790 \\
\hline Thermal conductivity $\left(\mathbf{W} / \mathbf{m}^{\circ} \mathbf{C}\right)$ & 0.21 \\
\hline Specific heat $\left(\mathbf{k J} / \mathbf{k g}^{\circ} \mathbf{C}\right)$ & 2.3 \\
\hline
\end{tabular}

124

\section{2 $\mathrm{CuO}$ nanoparticles}

Many researchers("<Enhancements of thermal conductivities with $\mathrm{Cu}, \mathrm{CuO}$. pdf $>$," ; Ghaderian \& Sidik, 2017)

Adding nanomaterials into the PCM to improve the thermos-physical properties of heat storage materials. Hence improves the performance of the system in the long run of operation and obtains high thermal storage efficiency. According to Fig 1, by (Olfian et al., 2020) $\mathrm{CuO}$ is more common in ETSC, due to high thermal conductivity is related to its price and preparation method. In this experiment, $\mathrm{CuO}$ Nano- enhanced PCM was used $0.2 \%$ by weight of paraffin wax to improve the thermal conductivity and heat transfer. This ratio was chosen for two reasons. The first reason is that the cost of the solar heater is economical, as the cost of the nano is relatively expensive. The second reason is that increasing the concentration of $\mathrm{CuO}$ nanoparticles leads to a decrease in the melting and solidification temperature of paraffin and thus lowers the sensible and latent heat respectively(Mandal et al., 2019)

Table 2 shows characteristic of $\mathrm{CuO}$ nanoparticles.

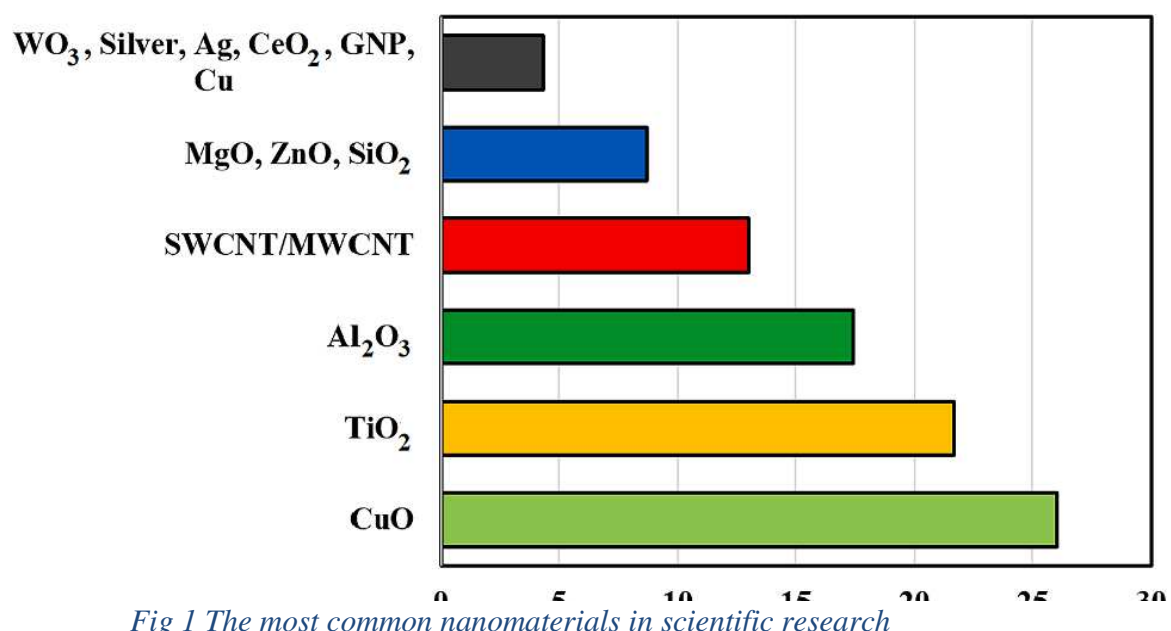




\begin{tabular}{|c|cc|}
\hline Property & \multicolumn{2}{|c|}{ Specification } \\
\hline Appearance & Black powder & 149 \\
\hline Avg. Size & $45 \pm 7 \mathrm{~nm}$ & 150 \\
\hline Density & $6300 \mathrm{~kg} / \mathrm{m}^{3}$ & \\
\hline Melting Point & $1250{ }^{\circ} \mathrm{C}$ & 151 \\
\hline Boiling Point & $2000{ }^{\circ} \mathrm{C}$ & 152 \\
\hline Thermal conductivity & $33 \mathrm{~W} / \mathrm{m} \mathrm{K}$ & \\
\hline
\end{tabular}

\section{$2.3 \quad N E-P C M$ preparation}

To fill all the tubes in this experiment, the volume produced between the first and second aluminum tubes was calculated. Approximately $2.5 \mathrm{~kg}$ of paraffin wax was used and 5 grams of $\mathrm{CuO}$ nanoparticles were added as $0.2 \%$ by weight. The ultrasonic vibrator type (TELSONIC ULTRASONICS CT-I2) is used for mix CuO nanoparticles with paraffin wax under temperature $60{ }^{\circ} \mathrm{C}$ and frequency $30 \mathrm{KHz}$. To ensure homogeneous mixing the device was used for 2 hours, and the paraffin wax color turned into black. Fig 2 depicts the steps of the compound's development, beginning with the solid state of paraffin wax and then heating it until it becomes a liquid, following which nanoparticles were added and well mixed till the compound turned black.

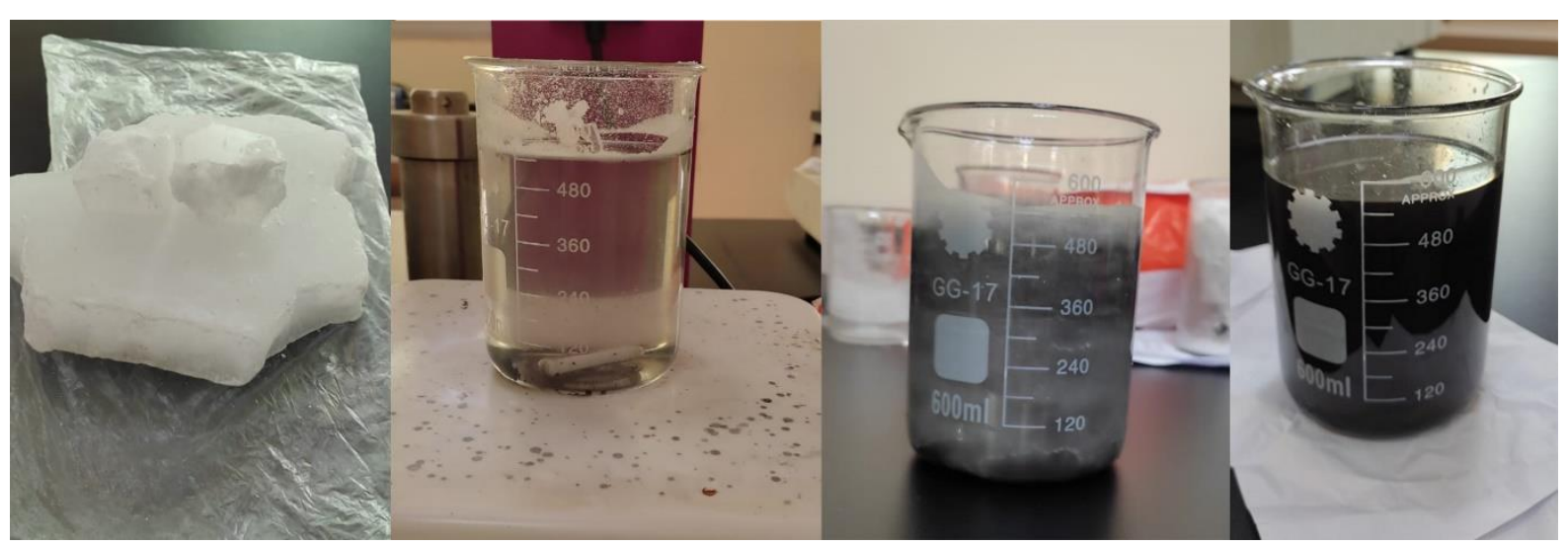

Fig 2 the stages of formation of the NE-PCM compound

\subsection{Centrifugal air pump}

The first step in choosing a fan is to figure out how much overall airflow it needs to deliver. To calculate the overall airflow demand, select an airflow rate, estimate the total quantity of application to be serviced by the fan, and multiply the airflow rate by the needed quantity.

The second step to selecting the fan is to determine the fan pressure needed to feed all the pipes in the system. The relation between the mass flow rates and the pressure drop is direct proportion. Moreover, the number of 
tubes in the system need a higher pressure to avoid the negative impact of pressure drop. Other factors such as pump size, purchase price and noise can also be considered, but the most important factor is the flow rate that is proportional to the expected operating pressure. In this experimental has been used air pump (650 W/13000 $\mathrm{rpm}$ ) and volume flow rate is $2.8 \mathrm{~m}^{3} / \mathrm{min}$ as maximum value, flow rates were changed to various value by pneumatic control valve.

\section{Experimental work}

\subsection{Design of ETSC system}

The experimental system consists of five units; each unit contained an evacuated tube with $1800 \mathrm{~mm}$ in length, 58 and $47 \mathrm{~mm}$ outer and inner diameter respectively. All the tubes are inserted with two aluminum coaxial pipe of length $1700 \mathrm{~mm}$. The first is $16 \mathrm{~mm}$ and the second is $30 \mathrm{~mm}$ in diameter were welded together to form one concentric pipe and installed inside the vacuum tube as shown in Fig 3.The empty volume between the two conjoined aluminum pipes shall be filled with NE-PCM. Table 3 presents the specifications of the design.

Experimental Stand was made from aluminum metal, taking into account the right dimensions of the design as follows: 1470 -length $\times 850$ high $\times 750 \mathrm{~mm}$ wide and $30^{\circ}$ as inclined angle on the horizontal as suggested by (Bracamonte, Parada, Dimas, \& Baritto, 2015). The evacuated tubes were set on the structure with the appropriate safeguards for non-movement induced by wind or environmental conditions in consideration. The schematic and photographic view of the setup shown in Fig 4 


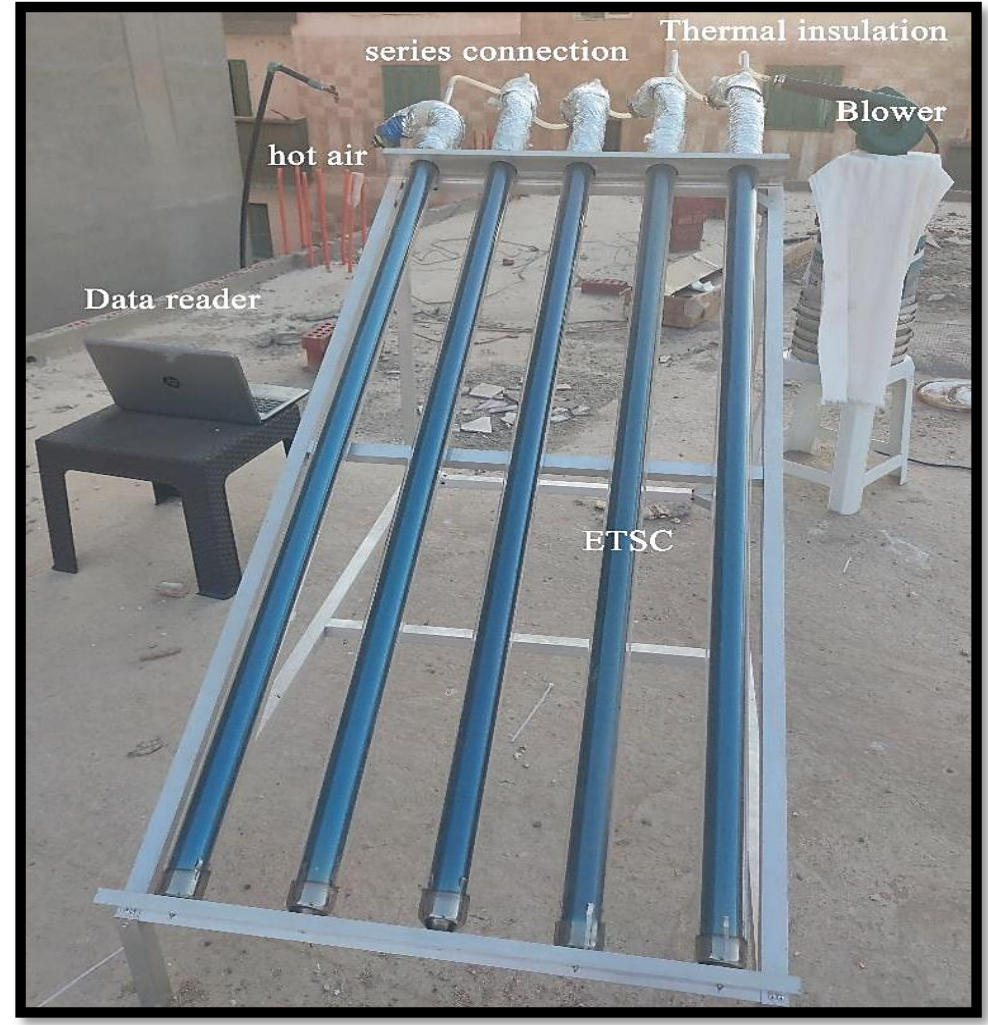

Fig 3 Photograph of the experimental work

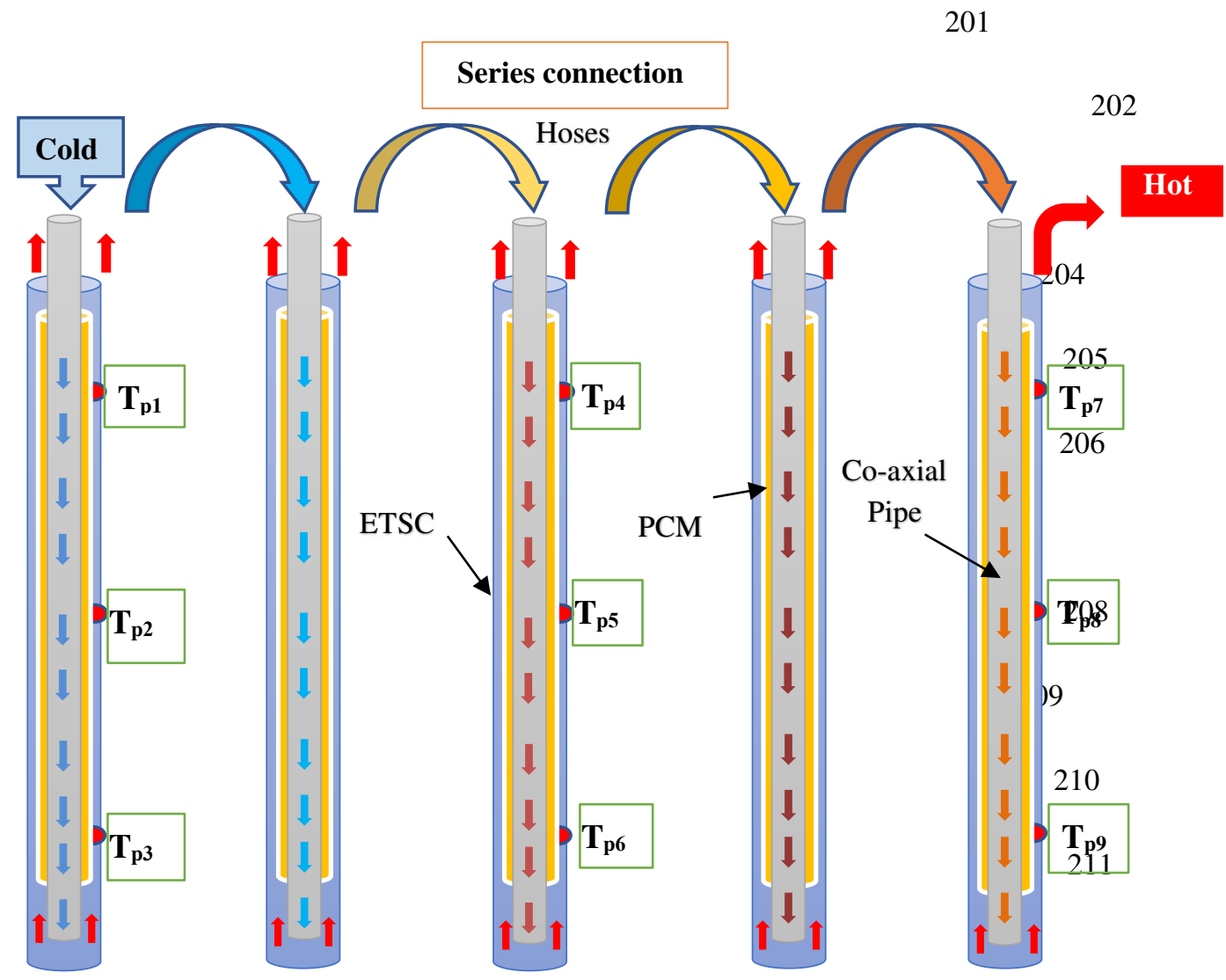

Fig 4 schematic of experiment design 
Fig 5 Schematic of the air path inside the unit

\subsection{Experimental procedure} $\left(31.416667^{\circ} \mathrm{N}, 31.821389^{\circ} \mathrm{E}\right)$, Egypt. $^{\circ}$

The system operation begins with the centrifugal pump running to flow air into the first co-axial pipe (concentric tube) into the vacuum tubes, which in turn absorbs heat and gains it on the aluminum pipe .Air is pumped to passes through each units on a connecting track about 18 meters long. In addition, that coated with thermal insulation from the outside to reduce heat loss. Added a layer of metal mesh between the vacuum tube and aluminum pipe for more stability, and the swirling air to enhance heat transfer. The necessary filling has been placed and provided with the gaskets and rubber all test areas are sealed tightly to ensure no air leakage. Heat is transmitted to the inlet air by thermal conduction from the axial tube and when exited the air gets the heat coming directly from the vacuum tube. In other words, the inlet air runs two flights, once while entering the axial pipe and the second as it exits the vacuum tube, heading for the next unit. Therefore, the airflow inside the single pipe exceeds 3.5 meters. This means that the total distance traveled by the airflow into the five pipes is approximately $18 \mathrm{~m}$ during which the heat is gained. A blower is connected at the inlet of the header using $65 \mathrm{~mm}$ diameter flexible air hose and provided with a manually operated ball valve that regulates the rate of airflow. This experiment was done in Kafr El-Sheikh on the roof of the faculty engineering at Kafr El-Sheikh University

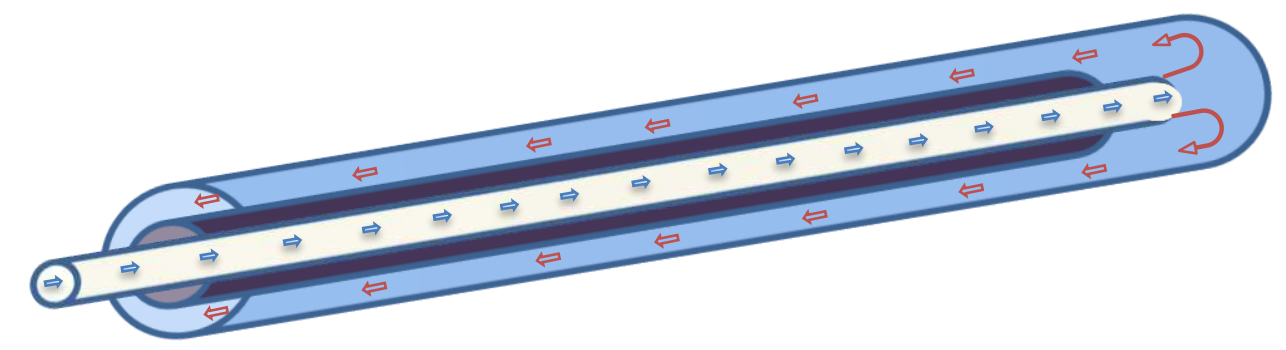

\begin{tabular}{|l|l|}
\hline Specifications of test rig & Value \\
\hline \multicolumn{2}{|c|}{ Evacuated tube } \\
\hline Number of tubes & 5 \\
\hline Length & $1800 \mathrm{~mm}$ \\
\hline Outer Diameter $\left(D_{0}\right)$ & $58 \mathrm{~mm}$ \\
\hline Inner Diameter $\left(D_{i}\right)$ & $47 \mathrm{~mm}$ \\
\hline
\end{tabular}




\begin{tabular}{|c|c|}
\hline Collector area $\left(\mathrm{A}_{\mathrm{c}}\right)$ & $0.82 \mathrm{~m}^{2}$ \\
\hline Tube material & Borosilicate glass \\
\hline Transmittance $(\tau)$ & 0.90 \\
\hline Emissivity $(\varepsilon)$ & 0.045 \\
\hline Absorptivity $(\alpha)$ & 0.94 \\
\hline \multicolumn{2}{|c|}{ Co-axial Aluminum pipe } \\
\hline Outer Diameter & $16 \mathrm{~mm}$ \\
\hline Inner Diameter & $3 \mathrm{~mm}$ \\
\hline Length & $1700 \mathrm{~mm}$ \\
\hline \multicolumn{2}{|c|}{ Structure frame } \\
\hline Dimensions & $1470 \times 850 \times 750 \mathrm{~mm}$ \\
\hline Inclined angle & $30^{\circ}$ \\
\hline Material & Aluminum \\
\hline \multicolumn{2}{|c|}{ Blower } \\
\hline Power output & $620 \mathrm{~W}$ \\
\hline No-load speed & $13000 / \mathrm{min}$ \\
\hline Max .air flow & $2.8 \mathrm{~m}^{3} / \mathrm{min}$ \\
\hline
\end{tabular}

\subsection{Measuring instruments}

This experience has been implemented and measured variables and results during the day from 7:00 Am to

240 5:00 Pm. The duration between each of them is 2 hours and comparing the results with the change in solar radiation

241 intensity and different mass flow rates. Arduino software records and transfers measurement data to a computer

242 display. All sensors are connected to the Arduino board and connect them to the computer to read the data. The temperature sensors were placed between each tube inside the connector hose to read out data for each separate tube. In addition to putting sensors inside the NE-PCM to measure its temperature during the day. The flow inlet and outlet temperatures of every unit were measured using LM35 temperature sensors of accuracy $\pm 0.5^{\circ} \mathrm{C}$. Two temperature sensors have been installed at the entry and exit of the unit for measured temperature rise $(\Delta \mathrm{T})$. The results were recorded as integer numbers and the decimal fractures were rounded. PYR-1307 pyranometer of $\pm 10 \mathrm{~W} / \mathrm{m}^{2}$ accuracy used to detect the intensity of solar radiation. In addition, wind speed of the surrounding across the surface of the collector is measured by anemometer PS-2174 weather anemometer with $\pm 3 \%$ accuracy of reading. BMP280 and DH22 sensors measure the pressure and humidity respectively; the sensor used in this experiment has low cost and high precision at medium and low temperature. 

characteristic of used sensors in the experimental.

\begin{tabular}{|l|l|l|l|}
\hline Sensor & Measurement & Range & Accuracy \\
\hline LM35 & Temperature & $-55-150$ & $\mathbf{\pm 0 . 5} \mathbf{C}$ \\
\hline DH22 & Humidity & $0-100 \%$ & $\pm \mathbf{2 - 5 \%}$ \\
\hline BMP280 & Pressure & $30-110 \mathrm{kpa}$ & $\mathbf{\pm 1 0} \mathbf{~ p a}$ \\
\hline Anemometer & Wind speed & $0.5-29 \mathrm{~m} / \mathrm{s}$ & $\mathbf{\pm 3 \%}$ \\
\hline Pyranometer & Solar radiation intensity & $0-1400 \mathrm{~W} / \mathrm{m}^{2}$ & $\pm 10 \mathrm{~W} / \mathrm{m}^{2}$ \\
\hline
\end{tabular}

\subsection{Error analysis}

The instrumental error, environmental variables, measurement and observation errors, adequate experimental design etc. have caused experimental uncertainty. In this investigation, several sources of uncertainty were addressed throughout tests such as temperature, humidity, air velocity, intensity of radiation, pressure drop and mass flow rate. The overall measurement of uncertainty and error analysis was carried out in the way reported in Ref. (I. Singh \& Vardhan, 2021).

Thus, the error of direct and indirect measurements can be calculated according to equation (1) and Table 4.

$\frac{\delta R}{R}=\sqrt{\left(\frac{\partial R}{\partial x_{1}} \delta x_{1}\right)^{2}+\left(\frac{\partial R}{\partial x_{2}} \delta x_{2}\right)^{2}+\cdots+\left(\frac{\partial R}{\partial x_{n}} \delta x_{n}\right)^{2}}$

Where $\partial \mathrm{x}_{1}, \partial \mathrm{x}_{2} \partial \mathrm{x}_{3} \ldots . \partial \mathrm{x}_{\mathrm{n}}$ are feasible errors in measurements of $\mathrm{x}_{1}, \mathrm{x}_{2}, \mathrm{x}_{3}, \mathrm{x}_{\mathrm{n}} \ldots \partial \mathrm{R}$ is known as absolute uncertainty and $\delta \mathrm{R} / \mathrm{R}$ is known as relative error and shown in Table 5

\begin{tabular}{|c|c|c|}
\hline Parameter & Unit & Relative Error \\
\hline Intensity of radiation & $\mathrm{W} / \mathrm{m}^{2}$ & $2 \%$ \\
\hline Temperature & ${ }^{\circ} \mathrm{C}$ & $0.5 \%$ \\
\hline Pressure & $\mathrm{pa}$ & $1 \%$ \\
\hline Humidity & - & $2-5 \%$ \\
\hline Velocity & $\mathrm{m} / \mathrm{s}$ & $2 \%$ \\
\hline
\end{tabular}




\section{Thermal efficiency calculations with and without NE-PCM}

It is clear that the thermal efficiency is the ratio of useful thermal energy gain by the fluid to heat absorbed by the solar collector area and intensity of radiation. The thermal efficiency of the system increases as the mass flow rates increase. The reason for this is that a reduction in pressure produces an increase in pumping power. The intensity of the solar radiation also increases the efficiency; where the maximum value appeared at 13:00 am. To calculate the total thermal energy gain, $\left(\mathrm{Q}_{\mathrm{g}}\right)$ from system as a whole can be used

$$
Q_{g}=\dot{m} C_{p}\left(T_{o}-T_{i}\right)(2)
$$

Where $\mathrm{T}_{\mathrm{o}}-\mathrm{T}_{\mathrm{i}}\left({ }^{\circ} \mathrm{C}\right)$ is the difference between outlet and inlet temperatures. $\dot{m}$ denotes the mass flow rate $(\mathrm{kg} / \mathrm{s})$,

$\mathrm{C}_{\mathrm{P}}$ is specific heat of air $\left(\mathrm{J} / \mathrm{kg} .{ }^{\circ} \mathrm{C}\right)$.The amount of actual thermal energy is absorbed by ETSC $\mathrm{Q}_{\mathrm{a}}(\mathrm{J})$ can expressed by

$Q_{a}=R A_{c} N$

Where $\mathrm{R}$ is solar of radiation $\left(\mathrm{W} / \mathrm{m}^{2}\right), \mathrm{A}_{\mathrm{c}}$ is area of collector and $\mathrm{N}$ is number of evacuated tubes.(Dhiman, Thakur, Kumar, \& Singh, 2011)

After subtracting losses from gained energy can express the actual energy gain $Q_{a}$, by

$Q_{a}=\dot{m} C_{p}\left(T_{o}-T_{i}\right)-\frac{P_{m}}{C}$

Where $\mathrm{P}_{\mathrm{m}}(\mathrm{W})$ denotes the mechanical power, calculated from pressure losses $\Delta \mathrm{P}\left(\mathrm{N} / \mathrm{m}^{2}\right)$ and volumetric flow rate $v\left(\mathrm{~m}^{3} / \mathrm{s}\right)$ as follows: (Vijayan, Arjunan, Kumar, \& Matheswaran, 2020)

$$
P_{m}=\Delta P \frac{\dot{m}}{\rho}
$$

The conversion factor $\mathrm{C}$ considering various efficiencies (thermal to mechanical) and is taken 0.2 (Gupta

\& Kaushik, 2009).

The pressure drop can be calculated by taking the diameter $\mathrm{D}$ and the length L into account may be computed as follows (Bagherzadeh et al., 2019; Batchelor \& Batchelor, 2000):

$$
\Delta P=f\left(\frac{L \rho V^{2}}{2 D}\right)
$$

Where $\rho, \mathrm{V}$ and $\mathrm{f}$ denote the density, velocity and the friction coefficient, respectively. The friction coefficient for smooth pipes may be determined as follows.

$$
f=0.316 R e^{-0.25}
$$

In which $R e=\frac{\rho V D}{\mu}$ 

the following:

$$
\eta_{c}=\frac{Q_{\text {gain }}}{Q_{\text {actual }}}
$$

Because PCM have sensible and latent heat, the beneficial heat gain when engaging Ne-PCM may be separated into three parts: When the PCM are in a solid state, heat gain is represented as

$$
Q_{g, p c m}=m_{p c m} C_{p, p c m}\left(T_{o}-T_{i}\right)_{p c m}
$$

06

$$
Q_{g, p c m}=m_{p c m} L_{p c m}
$$

Where $L_{P C M}$ is the latent heat for PCM in $(\mathrm{J} / \mathrm{kg})$

$$
\eta_{p c m}=\frac{\dot{m} C_{p}\left(T_{o}-T_{i}\right)-\frac{P m}{C}}{R A_{c} N+m_{p c m} C_{p, p c m}\left(T_{o}-T_{i}\right)_{p c m}+m_{p c m} L_{p c m}}
$$

\section{$5 \quad$ Result and discussion}

The experiments was based on connecting the tubes to each other and the changes caused by each individual tube were observed after the air passed through them. The thermal and hydraulic performances of the ETSC solar air heater in the time interval from 7:00 to 17:00 are evaluated based on the temperature rise and thermal efficiency during the months of June, July and August 2021. The effect of weather condition, mass flow rate, solar radiation and number of tubes on the thermal performance was also studied in the subsequent sections. The results were compiled daily, every two hours under different climatic conditions such as ambient temperature $\left(\mathrm{T}_{\mathrm{a}}\right) 30-40{ }^{\circ} \mathrm{C}$, humidity(H) 50-70\%, wind speed (Ws) $1-3 \mathrm{~m} / \mathrm{s}$ and solar radiation intensity (R) $950-1120 \mathrm{~W} / \mathrm{m}^{2}$. While presenting the results of the experiment, will focus on comparing the results in the month of July in particular, since it was the most radiant and compatible with the optimum temperatures. The ambient temperature and thermal efficiency increase directly with the solar radiation as discussed in (Abi Mathew \& Thangavel, 2021). In the month of July, the ambient temperature was recorded between $36-40{ }^{\circ} \mathrm{C}$. Table 6 lists the average values during the months of the experiment for solar radiation, ambient temperature, wind speed and humidity. Solar flux starts from 7:00 to 17:00; this means the ability to extract solar energy about 10 hours a day. Experimental measurements results have been recorded every two hours due to it does not happen substantial change in the solar radiation only after the passage of almost two hours. 


\begin{tabular}{|l|l|l|l|}
\hline Parameter in average value & June & July & August \\
\hline Solar radiation & $1034 \mathrm{~W} / \mathrm{m}^{2}$ & $1070 \mathrm{~W} / \mathrm{m}^{2}$ & $992 \mathrm{~W} / \mathrm{m}^{2}$ \\
\hline Ambient temperature & $34{ }^{\circ} \mathrm{C}$ & $38^{\circ} \mathrm{C}$ & $31^{\circ} \mathrm{C}$ \\
\hline Wind speed & $1.5 \mathrm{~m} / \mathrm{s}$ & $1.8 \mathrm{~m} / \mathrm{s}$ & $2.5 \mathrm{~m} / \mathrm{s}$ \\
\hline Humidity & $63 \%$ & $68 \%$ & $52 \%$ \\
\hline
\end{tabular}

\subsection{Effect of weather conditions on outlet temperature}

The outcomes resulted in an increase in the outlet temperature from $7 \mathrm{am}$ to $13 \mathrm{pm}$ in the afternoon, after that, the intensity of solar radiation gradually decreases but the outlet temperature remains very close until $15 \mathrm{pm}$. The outlet temperature for the system remains slightly good thanks to the presence of storage materials that derive energy until the disappearance of radiation at 17pm. Fig 6 shows the outlet temperatures with the onset of solar radiation until sunset, in other words, during the charging cycle for storage materials. In the period between 19 pm and $1 \mathrm{am}$, the outlet temperature drops rapidly with no storage materials. In contrast, the outlet temperature gradually decreases with the presence of NE-PCM. Fig 7 shows ambient temperatures with solar radiation changes and their impact on the outlet temperature.

After nearly two hours of sunset at $19 \mathrm{pm}$, the outlet temperature with storage materials is almost equal to the outlet temperature without storage material. This is due to the good thermal connectivity of aluminum, which maintains its warming for two hours after sunset. In the next part, results are discussed at different flow rates and approximately equal climatic conditions.

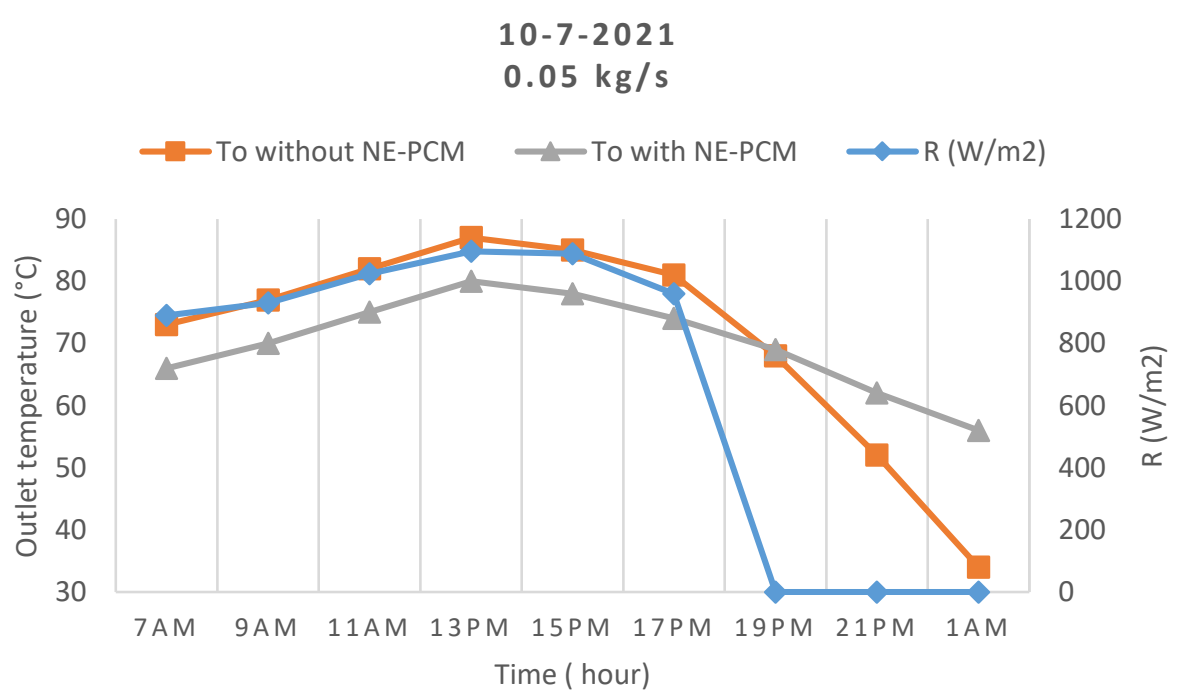

Fig 6 Outlet temperatures variation during the day as solar radiation changes 


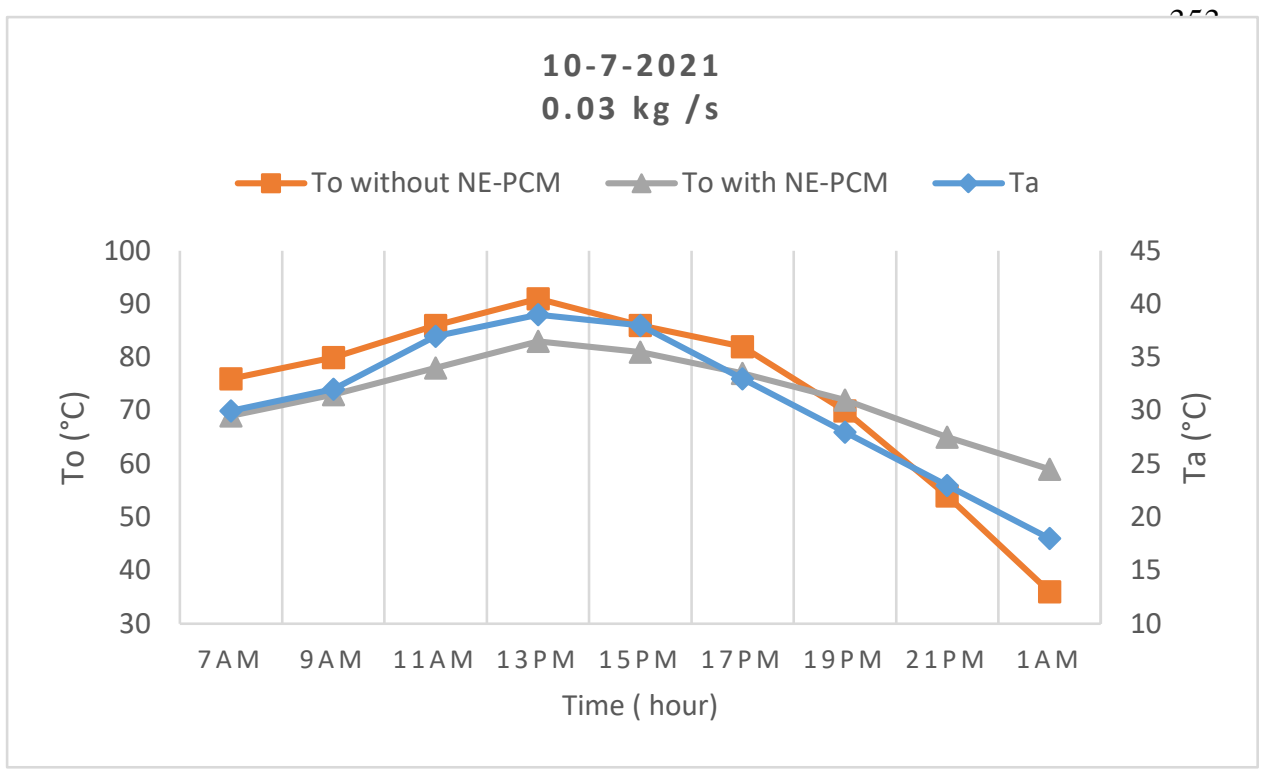

Fig 7 Outlet temperatures variation with and without NE-PCM as ambient temperature changes

\subsection{Effect of mass flow rate on outlet temperature}

The experiment was run on five different flow rates during the same day and under close conditions to observe the effect of flow rates on the outlet temperature with and without NE-PCM. The mass flow rate is one of the main influencing parameters of the output temperature in the vacuum pipe system. The outlet temperature is inversely proportional to the flow rate of the mass where the temperature at the exit increases as the flow rate of the mass decreases due to the increased contact duration of the heat transfer. Fig 8 displays the effect of mass flow rate during the solar radiation is available in outlet temperature. This experimental study was conducted on five different mass flow rates $0.006,0.008,0.01,0.03,0.05 \mathrm{~kg} / \mathrm{s}$. The highest air outlet temperature was observed at 110 and $116{ }^{\circ} \mathrm{C}$ with and without NE-PCM respectively at a mass flow rate of $0.006 \mathrm{~kg} / \mathrm{s}$ where the solar radiation was $1120 \mathrm{~W} / \mathrm{m}^{2}$ at 13:00 $\mathrm{pm}$, and then the temperature was reduced. The maximum values of outlet temperature at other mass flow rate was recorded in July at 13:00 pm without NE-PCM 96, 97, 102, and $116^{\circ} \mathrm{C}$ at mass flow rate $0.05,0.03,0.01$ and $0.008 \mathrm{~kg} / \mathrm{s}$, respectively.

The ambient temperature cannot ignored because it has also had an effect in raising temperatures. The rise in temperature is noticeable when there is a change in flow rates, but the solar radiation has little effect at the beginning of the day, and the effect begins to be observed at midday, due to the continuous movement of the sun and thus irregular absorption of radiation. 

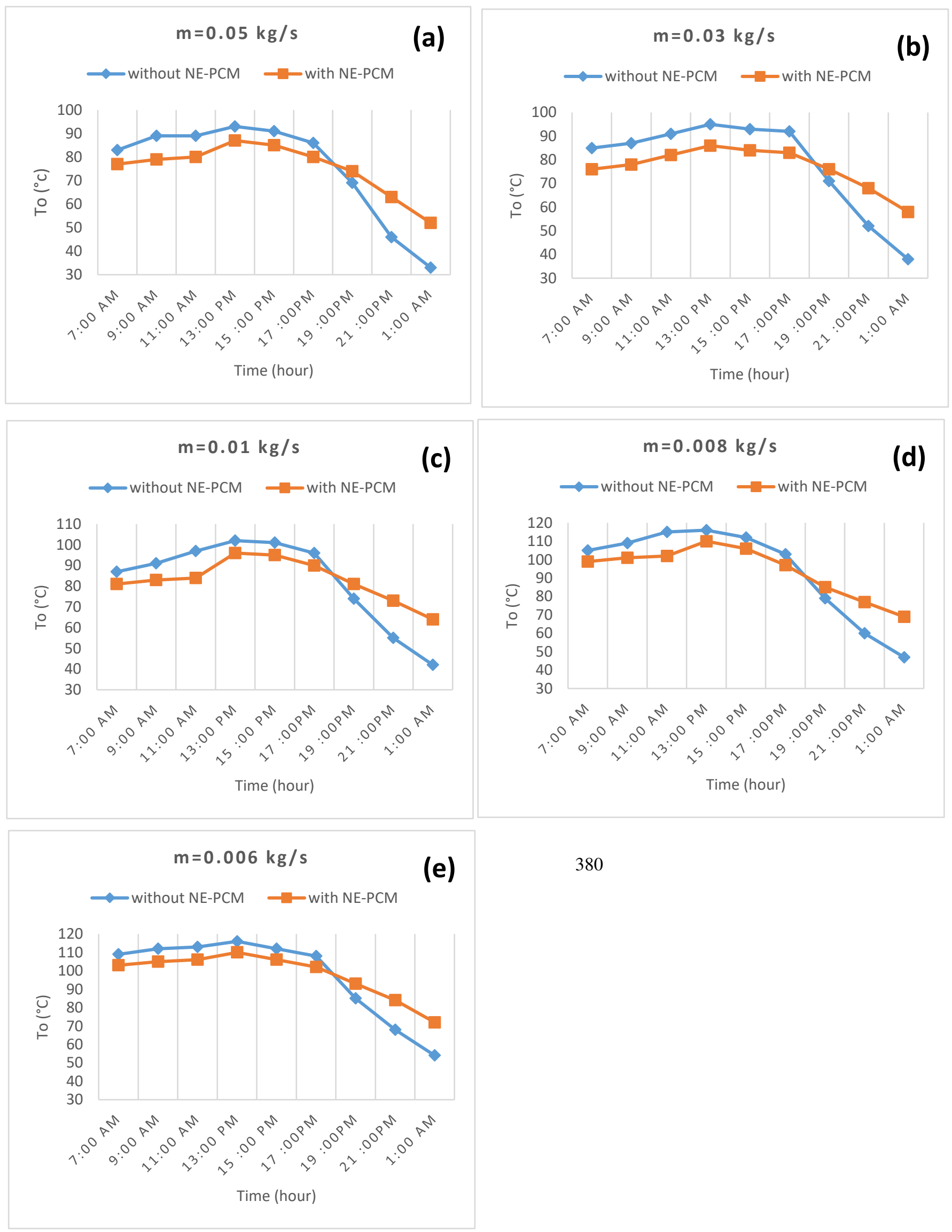

Fig 8 Effect of mass flow rate on outlet temperature (To) at (a) $0.05 \mathrm{~kg} / \mathrm{s}$, (b) $0.03 \mathrm{~kg} / \mathrm{s}$, (c) $0.01 \mathrm{~kg} / \mathrm{s}$, (d) $0.008 \mathrm{~kg} / \mathrm{s}$ and (e) $0.006 \mathrm{~kg} / \mathrm{s}$ 


\subsection{NE-PCM temperature during the charge and discharge process}

During the charging process before operating the system, NE-PCM acquires the heat from the solar flux and stores it, so the NE-PCM begins to melt from the top of the tube to the bottom. The temperature of the NE-PCM is derived from the ambient temperature until a solar flux is generated, and its temperature begins to rise. The temperature of NE-PCM within the units was measured for a whole day without the system running until temperature change is observed as shown in Fig 9. The temperature sensors were placed within the storage material at the top of the unit, middle and down to monitor the temperature change in storage material during operation in different flow rates as shown in Fig 10.

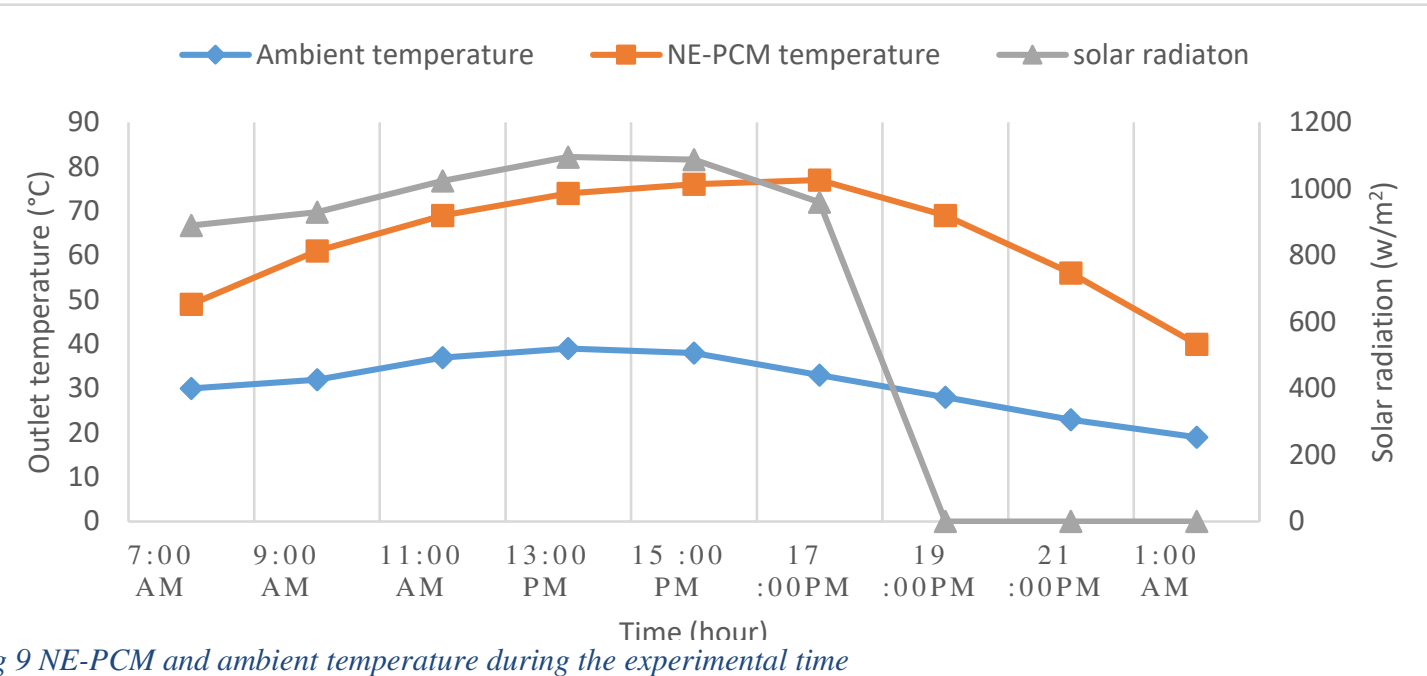

401

In addition, the highest temperature of NC-PCM was set at $17: 00 \mathrm{pm} 83,86$ and $96{ }^{\circ} \mathrm{C}$ for the first unit, third and fifth respectively. After that, the temperature of NE-PCM decreases gradually and almost similarly in the five units, till the NE-PCM loses its heat and turns again to the solid-state. The temperature was measured at 1 am, while it ranged between $42-48^{\circ} \mathrm{C}$, and it was noted that the temperature of NE-PCM is always higher than the ambient temperature despite the absence of sunlight. All flow rates follow the same approach, temperature rise during the period of solar radiation from top to bottom and from the fifth to the first tube. At night, the 
416 The highest temperature of the storage material is observed at flow rates $0.008,0.01,0.03,0.05 \mathrm{~kg} / \mathrm{s}$ is 94,91 ,

41790 , and $89^{\circ} \mathrm{C}$ respectively. 

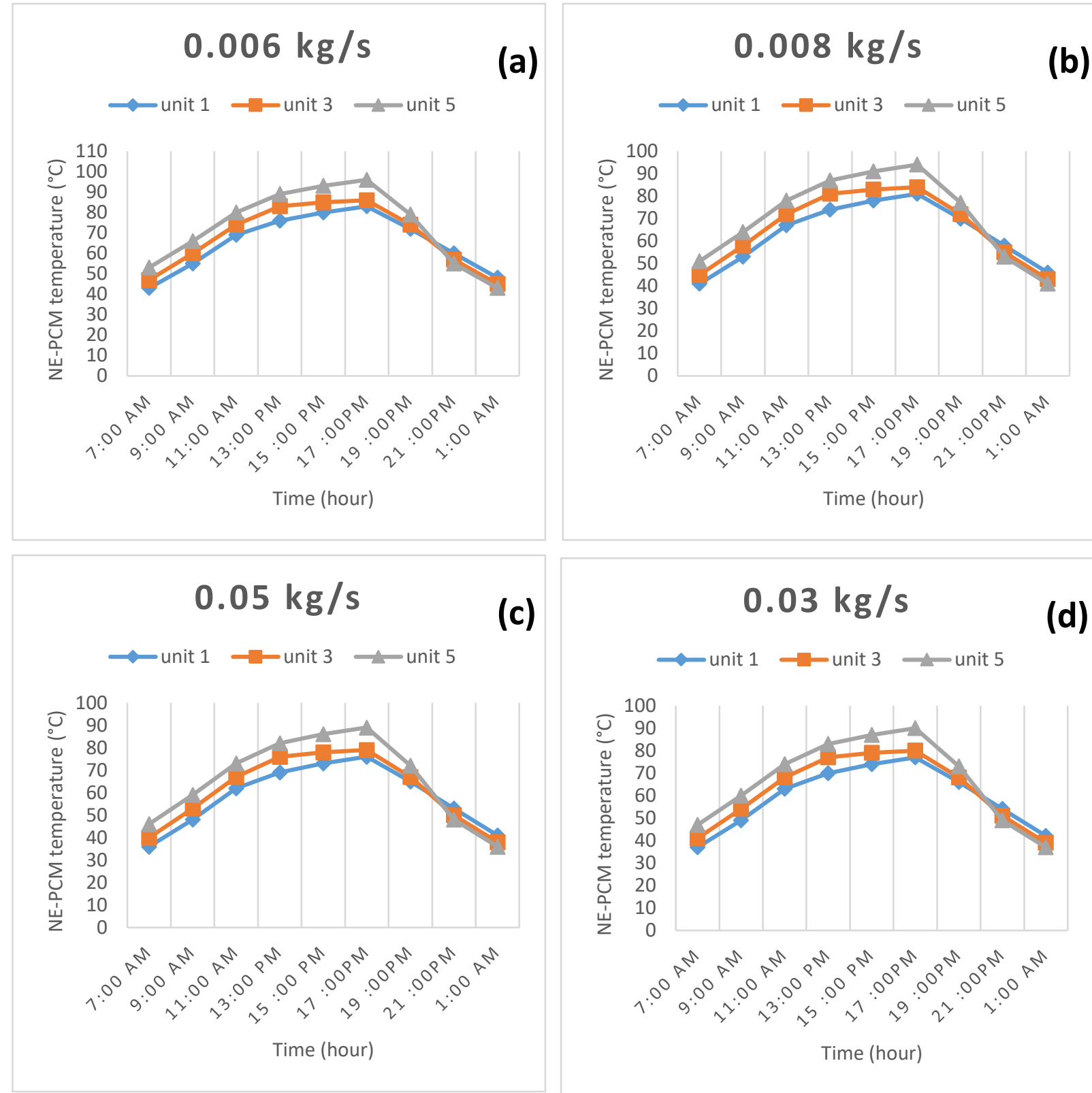

(b)
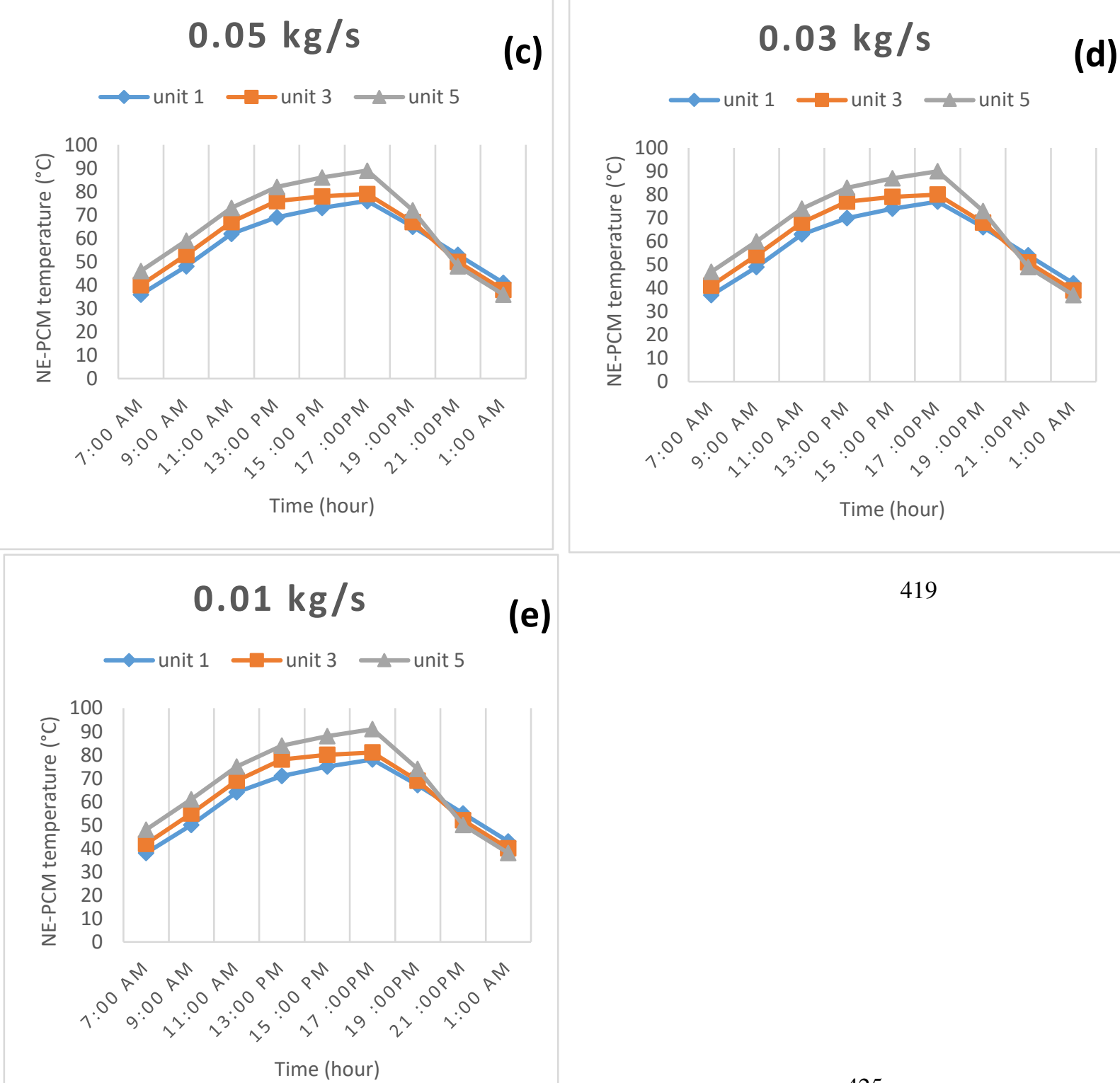

e)

419

Fig 10 NE-PCM temperatures in each unit while operating the system with different flow rates (a) $0.006 \mathrm{~kg} / \mathrm{s}$ (b) $0.008 \mathrm{~kg} / \mathrm{s}$ (c) $0.05 \mathrm{~kg} / \mathrm{s}$ (d) $0.03 \mathrm{~kg} / \mathrm{s}$ (e) $0.01 \mathrm{~kg} / \mathrm{s}$ 


\subsection{Thermal performance and storage efficiency}

427

Based on data obtained from the solar air heater experience with the evacuated tubes connected in series, when the system is operated at different flow rates and variable solar radiation during the day. Fig 11 and Fig 12 shows the comparison in the results of thermal efficiency during the day for the system with and without NEPCM as storage materials. It is noted that the addition of heat storage materials leads to an increase in the thermal efficiency of the system throughout the day compared to the absence of storage materials. This is because incorporating NE-PCM into the solar evacuated collector increases the system operational duration by supplying the system with thermal energy absorbed by storage materials when there is no solar radiation at night or cloudy day. Moreover, the incorporation of NE-PCM into solar collectors reduces heat loss returned via the heat pipe during the night when there is no solar radiation. It was recorded that the maximum daily thermal efficiency was achieved at an air flow rate of $0.05 \mathrm{~kg} / \mathrm{s}$ by $38 \%, 26 \%$ with and without NE-PCM, respectively. In the pipes connected in a series, the efficiency does not increase much for two main reasons; the first is the pressure drop, which causes a loss in the gained energy. The second is because the rise temperature does not increase sufficiently with the increase in solar radiation. It is also worth noting that the thermal efficiency of the pipes connected in a series increases significantly when the air flow rates are increased and the number of system units is reduced to overcome the pressure drop. On the other hand, this may lead to a relatively lower temperature outlet, but it remains qualified for domestic applications and also drying agricultural crops.

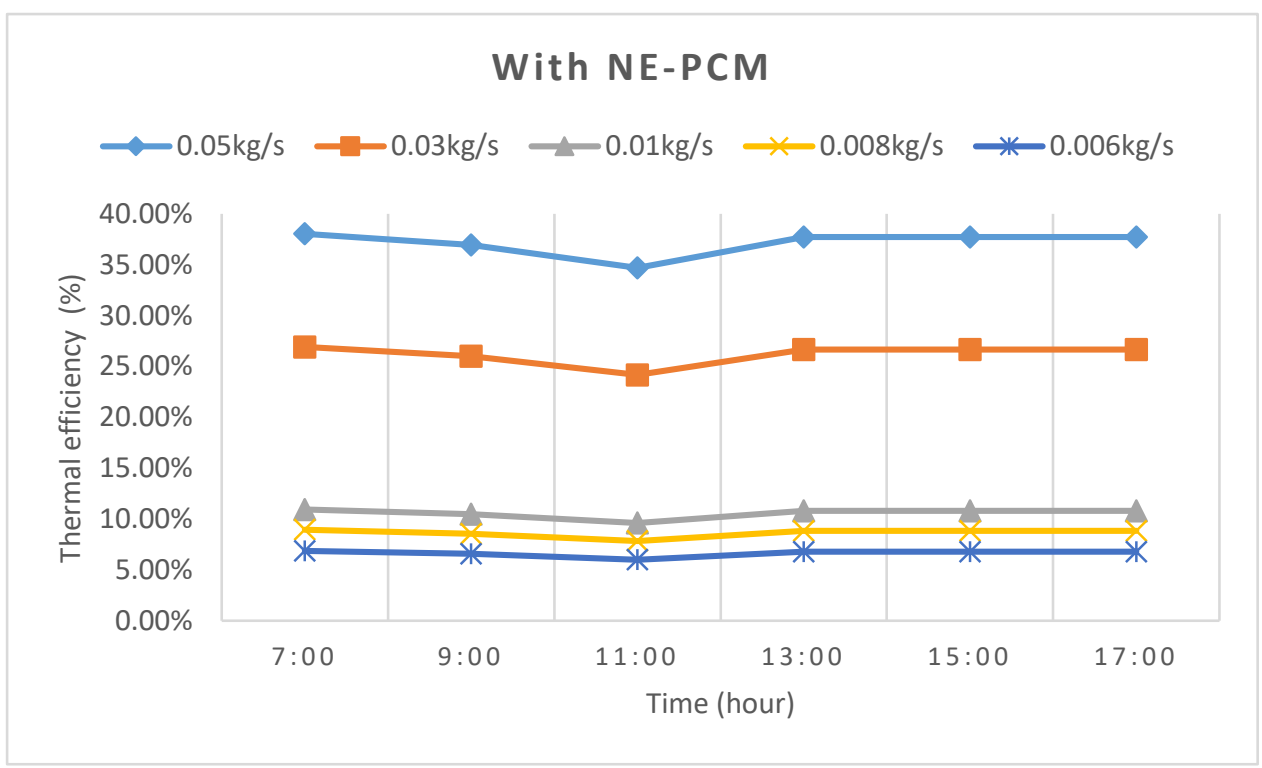

Fig 11 Thermal efficiency witht added storage material 


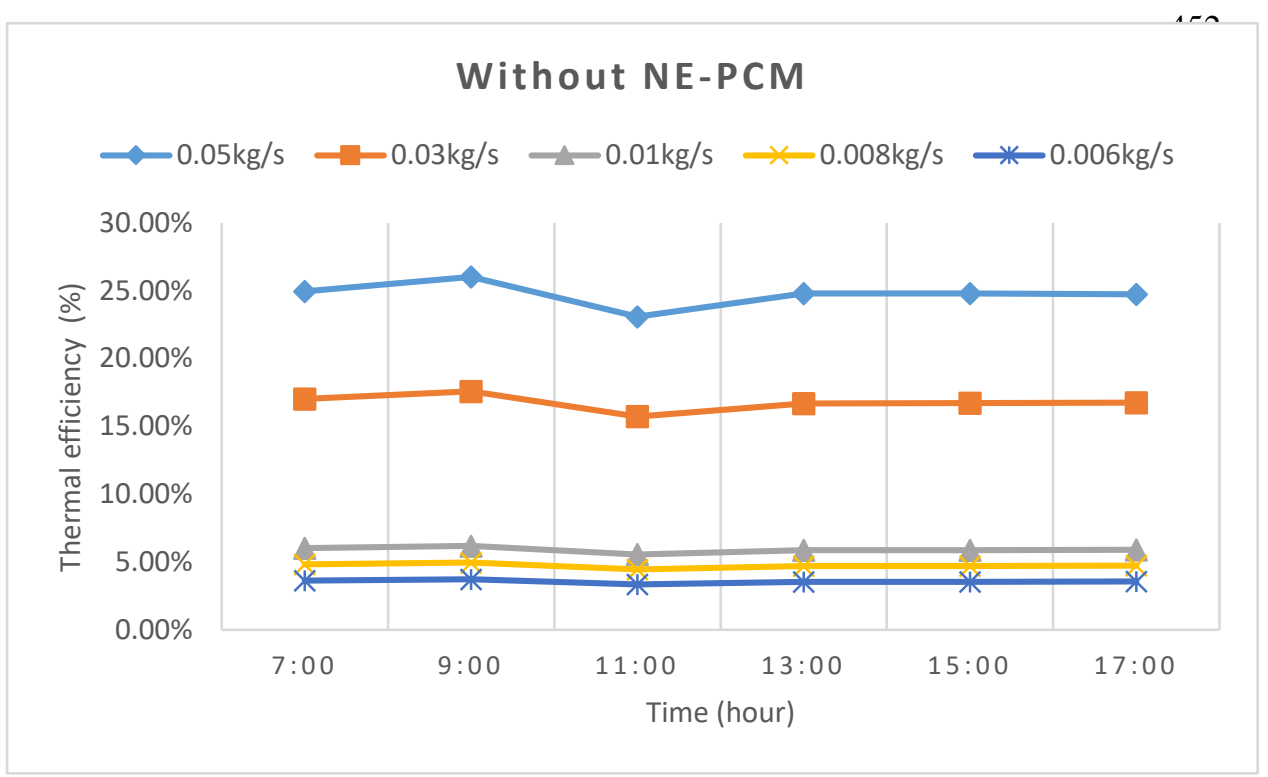

Fig 12 Thermal efficiency without added storage material

\section{Conclusion}

The experimental study was based on testing the performance efficiency of solar air heater with evacuated tube solar collector connected in series at different times during the day from 7:00 am to 17:00 pm when the solar radiation changes between $950-1120 \mathrm{~W} / \mathrm{m}^{2}$. The heat transfer in the system is enhanced by combining copper oxide nanoparticles with paraffin wax to improve the thermophysical properties and increasing the distance of air travels inside the system units for heat exchange. Connecting evacuated tube in series showed a rise in temperatures when the number of tubes increased. By comparing and analyzing the results at five different mass flow rates taking into account the loss of pressure, it was observed that the temperature rises to the maximum value at a flow rate of $0.006 \mathrm{~kg} / \mathrm{s}$ as the whole system. While the temperature rise between each unit increases in the first pipe and then the increase will reduces with other pipes in series. Although this technique faces some challenges, including pressure drop, which affects the overall efficiency of the thermal performance; However, it should be highlighted in the installation of solar air heater because it remarkably effective in low and medium temperature applications. Some other conclusions are stated as below:

1- The proposed design achieved a maximum thermal efficiency of 38-26\% with and without NE-PCM respectively at a flow rate of $0.05 \mathrm{~kg} / \mathrm{s}$ and pressure drop was $2.2 \mathrm{kpa}$ of system as a whole. the efficiency of the collector decreases as the number of tubes increases, while the outlet temperature remains fixed or very little in rise. Therefore, we recommend applying this proposed system with three to five tubes only to obtain the best efficiency in series technique.

2- The highest temperature recorded $116,115,102,97$ and $96^{\circ} \mathrm{C}$ at $13: 00$, with a mass flow rate of 0.006 , $0.008,0.01,0.03$, and $0.05 \mathrm{~kg} / \mathrm{s}$ respectively by using 5 units in July Without adding NE-PCM.

3- The highest temperature for NE-PCM was $77^{\circ} \mathrm{C}$ without running the system and $96^{\circ} \mathrm{C}$ when the system is operated at an airflow rate of $0.006 \mathrm{~kg} / \mathrm{s}$. in addition the maximum outlet temperature was $110^{\circ} \mathrm{C}$ at $13 \mathrm{pm}$. 
4- The addition of $\mathrm{CuO}$ nanoparticles to the PCM integrated into evacuated solar collector gave an enhancement in the thermal conductivity and allowed to store more thermal energy, permitting to quickly retrieve the power after sunset.

5- In light of high-energy costs and strict emission standards, this design achieves alternative energy supply with low-cost equipment and easy installation system making it qualifications for solar air heater applications, such as heating system, drying and greenhouse.

\section{Declaration}

Ethical approval Not applicable.

Consent to participate Not applicable.

Consent to publish Not applicable.

Competing interests The authors declare no competing interests.

\section{Funding Not applicable}

\section{Authors Contributions}

Amr Elbrashy: Conducted all the experiments for evaluating the performance of the solar air heater Magda Elfakharany: Processing of storage materials (paraffin wax, copper oxide nanoparticles) and mixed into the lab

Fadl Essa: Writing, formal analysis and software

Fawzy Aboutaleb: review and editing

\section{Data availability}

The datasets used and/or analyzed during the current study are available from the corresponding author upon request.

\section{Reference}

Abdullah, A., Amro, M., Younes, M., Omara, Z., Kabeel, A., \& Essa, F. (2020). Experimental investigation of single pass solar air heater with reflectors and turbulators. Alexandria Engineering Journal, 59(2), 579587.

Abi Mathew, A., \& Thangavel, V. (2021). A novel thermal storage integrated evacuated tube heat pipe solar air heater: Energy, exergy, economic and environmental impact analysis. Solar Energy, 220, 828-842. doi: https://doi.org/10.1016/j.solener.2021.03.057 
Abokersh, M. H., El-Morsi, M., Sharaf, O., \& Abdelrahman, W. (2017). An experimental evaluation of direct flow evacuated tube solar collector integrated with phase change material. Energy, 139, 1111-1125. doi: https://doi.org/10.1016/j.energy.2017.08.034

Algarni, S., Mellouli, S., Alqahtani, T., Almutairi, K., khan, A., \& Anqi, A. (2020). Experimental investigation of an evacuated tube solar collector incorporating nano-enhanced PCM as a thermal booster. Applied Thermal Engineering, 180, 115831. doi: 10.1016/j.applthermaleng.2020.115831

Aramesh, M., \& Shabani, B. (2020). On the integration of phase change materials with evacuated tube solar thermal collectors. Renewable and Sustainable Energy Reviews, 132, 110135. doi: 10.1016/j.rser.2020.110135

Babapoor, A., Karimi, G., \& Sabbaghi, S. (2016). Thermal characteristic of nanocomposite phase change materials during solidification process. Journal of Energy Storage, 7, 74-81. doi: https://doi.org/10.1016/j.est.2016.05.006

Bagherzadeh, S. A., Sulgani, M. T., Nikkhah, V., Bahrami, M., Karimipour, A., \& Jiang, Y. (2019). Minimize pressure drop and maximize heat transfer coefficient by the new proposed multi-objective optimization/statistical model composed of "ANN + Genetic Algorithm" based on empirical data of $\mathrm{CuO} /$ paraffin nanofluid in a pipe. Physica A: Statistical Mechanics and its Applications, 527, 121056. doi: https://doi.org/10.1016/j.physa.2019.121056

Batchelor, C. K., \& Batchelor, G. (2000). An introduction to fluid dynamics: Cambridge university press.

Bracamonte, J., Parada, J., Dimas, J., \& Baritto, M. (2015). Effect of the collector tilt angle on thermal efficiency and stratification of passive water in glass evacuated tube solar water heater. Applied Energy, 155, 648-659. doi: 10.1016/j.apenergy.2015.06.008

Chaichan, M. T., Abaas, K. I., \& Kazem, H. A. (2016). Design and assessment of solar concentrator distillating system using phase change materials (PCM) suitable for desertic weathers. Desalination and Water Treatment, 57(32), 14897-14907. doi: 10.1080/19443994.2015.1069221

Chopra, K., Tyagi, V. V., Pathak, A. K., Pandey, A. K., \& Sari, A. (2019). Experimental performance evaluation of a novel designed phase change material integrated manifold heat pipe evacuated tube solar collector system. Energy Conversion and Management, 198, 111896. doi: https://doi.org/10.1016/j.enconman.2019.111896

Dhiman, P., Thakur, N. S., Kumar, A., \& Singh, S. (2011). An analytical model to predict the thermal performance of a novel parallel flow packed bed solar air heater. Applied Energy, 88(6), 2157-2167. doi: https://doi.org/10.1016/j.apenergy.2010.12.033

Dsilva Winfred Rufuss, D., Suganthi, L., Iniyan, S., \& Davies, P. A. (2018). Effects of nanoparticle-enhanced phase change material (NPCM) on solar still productivity. Journal of Cleaner Production, 192, 9-29. doi: https://doi.org/10.1016/j.jclepro.2018.04.201

$<$ Enhancements of thermal conductivities with $\mathrm{Cu}, \mathrm{CuO}$.pdf $>$.

Essa, M. A., Mostafa, N. H., \& Ibrahim, M. M. (2018). An experimental investigation of the phase change process effects on the system performance for the evacuated tube solar collectors integrated with PCMs. Energy Conversion and Management, 177, 1-10. doi: https://doi.org/10.1016/j.enconman.2018.09.045

Farid, M. M., Khudhair, A. M., Razack, S. A. K., \& Al-Hallaj, S. (2004). A review on phase change energy storage: materials and applications. Energy Conversion and Management, 45(9-10), 1597-1615. doi: 10.1016/j.enconman.2003.09.015

Ghaderian, J., \& Sidik, N. A. C. (2017). An experimental investigation on the effect of A12O3/distilled water nanofluid on the energy efficiency of evacuated tube solar collector. International Journal of Heat and Mass Transfer, 108, 972-987. doi: https://doi.org/10.1016/j.ijheatmasstransfer.2016.12.101

Gupta, M. K., \& Kaushik, S. C. (2009). Performance evaluation of solar air heater for various artificial roughness geometries based on energy, effective and exergy efficiencies. Renewable Energy, 34(3), 465-476. doi: https://doi.org/10.1016/j.renene.2008.06.001

Kalogirou, S. A. (2004). Solar thermal collectors and applications. Progress in Energy and Combustion Science, 30(3), 231-295. doi: https://doi.org/10.1016/j.pecs.2004.02.001

Khan, M. M. A., Ibrahim, N. I., Mahbubul, I. M., Muhammad. Ali, H., Saidur, R., \& Al-Sulaiman, F. A. (2018). Evaluation of solar collector designs with integrated latent heat thermal energy storage: A review. Solar Energy, 166, 334-350. doi: 10.1016/j.solener.2018.03.014

Korres, D., \& Tzivanidis, C. (2018). A new mini-CPC with a U-type evacuated tube under thermal and optical investigation. Renewable Energy, 128, 529-540. doi: https://doi.org/10.1016/j.renene.2017.06.054

Kumar, A., Tiwari, A. K., \& Said, Z. (2021). A comprehensive review analysis on advances of evacuated tube solar collector using nanofluids and PCM. Sustainable Energy Technologies and Assessments, 47, 101417. doi: https://doi.org/10.1016/j.seta.2021.101417

Li, B., \& Zhai, X. (2017). Experimental investigation and theoretical analysis on a mid-temperature solar collector/storage system with composite PCM. Applied Thermal Engineering, 124, 34-43. doi: https://doi.org/10.1016/j.applthermaleng.2017.06.002

Mandal, S. K., Kumar, S., Singh, P. K., Mishra, S. K., Bishwakarma, H., Choudhry, N. P., . . Das, A. K. (2019). Performance investigation of $\mathrm{CuO}$-paraffin wax nanocomposite in solar water heater during night. Thermochimica Acta, 671, 36-42. doi: https://doi.org/10.1016/j.tca.2018.11.003 
Mehla, N., \& Yadav, A. (2016). Thermal analysis on charging and discharging behaviour of a phase change material-based evacuated tube solar air collector. Indoor and Built Environment, 27(2), 156-172. doi: $10.1177 / 1420326 \times 16667626$

Mehla, N., \& Yadav, A. (2018). Thermal analysis on charging and discharging behaviour of a phase change material-based evacuated tube solar air collector. Indoor and Built Environment, 27(2), 156-172. doi: $10.1177 / 1420326 \times 16667626$

Nižetić, S., Jurčević, M., Arıcı, M., Arasu, A. V., \& Xie, G. (2020). Nano-enhanced phase change materials and fluids in energy applications: A review. Renewable and Sustainable Energy Reviews, 129, 109931. doi: 10.1016/j.rser.2020.109931

Olfian, H., Ajarostaghi, S. S. M., \& Ebrahimnataj, M. (2020). Development on evacuated tube solar collectors: A review of the last decade results of using nanofluids. Solar Energy, 211, 265-282. doi: https://doi.org/10.1016/j.solener.2020.09.056

Qureshi, Z. A., Ali, H. M., \& Khushnood, S. (2018). Recent advances on thermal conductivity enhancement of phase change materials for energy storage system: A review. International Journal of Heat and Mass Transfer, 127, 838-856. doi: https://doi.org/10.1016/j.ijheatmasstransfer.2018.08.049

Sharma, S., Kitano, H., \& Sagara, K. (2004). Phase Change Materials for Low Temperature Solar Thermal Applications. Res Rep Fac Eng Mie Univ, 29.

Singh, I., \& Vardhan, S. (2021). Experimental investigation of an evacuated tube collector solar air heater with helical inserts. Renewable Energy, 163, 1963-1972. doi: https://doi.org/10.1016/j.renene.2020.10.114

Singh, P., \& Gaur, M. K. (2021). Environmental and economic analysis of novel hybrid active greenhouse solar dryer with evacuated tube solar collector. Sustainable Energy Technologies and Assessments, 47, 101428. doi: https://doi.org/10.1016/j.seta.2021.101428

Veera Kumar, A., Arjunan, T. V., Seenivasan, D., Venkatramanan, R., \& Vijayan, S. (2021). Thermal performance of an evacuated tube solar collector with inserted baffles for air heating applications. Solar Energy, 215, 131-143. doi: https://doi.org/10.1016/j.solener.2020.12.037

Verma, S. K., Gupta, N. K., \& Rakshit, D. (2020). A comprehensive analysis on advances in application of solar collectors considering design, process and working fluid parameters for solar to thermal conversion. Solar Energy, 208, 1114-1150. doi: https://doi.org/10.1016/j.solener.2020.08.042

Vijayan, S., Arjunan, T. V., Kumar, A., \& Matheswaran, M. M. (2020). Experimental and thermal performance investigations on sensible storage based solar air heater. Journal of Energy Storage, 31, 101620. doi: https://doi.org/10.1016/j.est.2020.101620

Wang, P.-Y., Guan, H.-Y., Liu, Z.-H., Wang, G.-S., Zhao, F., \& Xiao, H.-S. (2014). High temperature collecting performance of a new all-glass evacuated tubular solar air heater with U-shaped tube heat exchanger. Energy Conversion and Management, 77, 315-323. doi: https://doi.org/10.1016/j.enconman.2013.08.019

Wang, P.-Y., Li, S.-F., \& Liu, Z.-H. (2015). Collecting performance of an evacuated tubular solar hightemperature air heater with concentric tube heat exchanger. Energy Conversion and Management, 106, 1166-1173. doi: https://doi.org/10.1016/j.enconman.2015.10.058

Wang, Z., Diao, Y., Zhao, Y., Chen, C., Liang, L., \& Wang, T. (2020). Thermal performance of integrated collector storage solar air heater with evacuated tube and lap joint-type flat micro-heat pipe arrays. Applied Energy, 261, 114466. doi: 10.1016/j.apenergy.2019.114466

Xiong, T., Zheng, L., \& Shah, K. W. (2020). Nano-enhanced phase change materials (NePCMs): A review of numerical simulations. Applied Thermal Engineering, 178, 115492. doi: 10.1016/j.applthermaleng.2020.115492

Yongtai, H., Lixian, X., \& Yaohua, Y. (2019). Study on design and thermal characteristics of vacuum tube solar collector intubated with heat storage tube. International Journal of Energy Research, 43(13), 74097420 . 